\title{
Diploid males of Scaptotrigona depilis are able to join reproductive aggregations (Apidae, Meliponini)
}

\author{
Ayrton Vollet-Neto', Charles Fernando dos Santos², Leandro Rodrigues Santiago ${ }^{3}$, \\ Denise de Araujo Alves',4, Julia Pinheiro de Figueiredo', Marino Nanzer', \\ Maria Cristina Arias $^{3}$, Vera Lucia Imperatriz-Fonseca ${ }^{1,5}$
}

I Departamento de Biologia, Faculdade de Filosofia, Ciências e Letras de Ribeiräo Preto, Universidade de São Paulo, Ribeirão Preto, SP, Brazil 2 Departamento de Biodiversidade e Ecologia, Pontifícia Universidade Católica do Rio Grande do Sul, Porto Alegre, RS, Brazil 3 Departamento de Genética e Biologia Evolutiva, Instituto de Biociências, Universidade de São Paulo, São Paulo, SP, Brazil 4 Departamento de Entomologia e Acarologia, Escola Superior de Agricultura "Luiz de Queiroz", Universidade de São Paulo, Piracicaba, SP, Brazil 5 Instituto Tecnológico Vale, Belém, PA, Brazil

Corresponding author: Ayrton Vollet-Neto (ayrtonneto@usp.br)

Academic editor: Jack Neff | Received 24 February 2015 | Accepted 12 April 2015 | Published 7 September 2015

http://zoobank.org/2BBF5610-2322-4EE4-ADEF-2E3ED90AC6EB

Citation: Vollet-Neto A, dos Santos CF, Santiago LR, Alves DA, de Figueiredo JP, Nanzer M, Arias MC, ImperatrizFonseca VL (2015) Diploid males of Scaptotrigona depilis are able to join reproductive aggregations (Apidae, Meliponini). Journal of Hymenoptera Research 45: 125-130. doi: 10.3897/JHR.45.4769

\begin{abstract}
The sex determination system in the eusocial stingless bees (Apidae, Meliponini) is based on the combination of alleles at the complementary sex determination (CSD) locus. In this system, males are haploid and females are diploid. However, diploid males can develop from fertilized eggs when they are homozygous at single or multiple sex loci. The production of such males can negatively affect population viability, since they are usually infertile or inviable. Moreover, when they are viable but infertile, or siring sterile triploid offspring, this could cause another load on the population, leading the fertilized offspring of other females to be only haploid males or triploid sterile daughters. In this context, our aim was to verify whether diploid males of the stingless bee Scaptotrigona depilis do in fact join reproductive aggregations. We showed that of 360 marked males from two different colonies, five were participating in a reproductive aggregation $c$. 20 meters from their natal colonies. Using microsatellites markers, it was confirmed that three of these five males were diploid. They were captured in the mating aggregations when they were 15 to 20 days old. Further research is necessary to determine the mating success of stingless bee diploid males under natural conditions and to determine their impact on stingless bee population extinction risks.
\end{abstract}

Copyright Ayrton Vollet-Neto et al. This is an open access article distributed under the terms of the Creative Commons Attribution License (CC BY 4.0), which permits unrestricted use, distribution, and reproduction in any medium, provided the original author and source are credited. 


\section{Keywords}

Inbreeding, diploid male load, population viability, stingless bees

\section{Introduction}

The system of sex determination in the eusocial stingless bees (Apidae, Meliponini) has been shown to be based on the combination of alleles at the complementary sex determination (CSD) locus (Camargo 1979), like many other Hymenoptera (Whiting 1943). Under this system, individuals that are heterozygotes at the CSD locus are females, while the hemizygotes (haploid individuals) and the homozygotes are males (Whiting 1943; Cook and Crozier 1995).

With few exceptions (El Agoze et al. 1994; Cowan and Stahlhut 2004; Kureck et al. 2013), diploid males are highly disadvantageous for the Hymenoptera species they occur in, imposing fitness costs on their relatives. Most of the time they are unviable, infertile or lead to the production of infertile triploid broods (Heimpel and de Boer 2008). They also lead to the decrease of females in the population, since the diploid individuals were supposed to develop into females, increasing the extinction risks of the population (Zayed and Packer 2005).

Simulation models have shown that extinction risks increase when diploid males are viable and can mate (Zayed and Packer 2005). This is expected because females mortality would increase over two generations, first in the diploid offspring that was supposed to be female but ends as an infertile diploid male, and secondly because the females that mate with diploid male would produce triploid daughters or only haploid males (Harpur et al. 2013). Indeed it has been shown that in several hymenopteran species the diploid males are able to mate (reviewed in Heimpel and de Boer 2008).

The extinction risks are even more extreme for stingless bees, since their nests are sparse and, together with habitat fragmentation, there are few effective population sizes (Packer and Owen 2001; Zayed 2009). It is well known that the queens mate only once in this group (Peters et al. 1999), causing half of their diploid brood to develop into diploid males when there is a matched mating (queen mating with a male with the same sex allele), greatly reducing their fitness (Cook and Crozier 1995) and increasing population extinction risks when there is low population size or low sex alleles variability (Alves et al. 2011). Therefore, to assess the effects of the diploid males on stingless bee conservation, it is important to know the viability of diploid males and their participation on the reproductive events. Despite some previous observations of aggressive behaviour of workers towards the diploid males in Melipona interrupta, suggesting that although the diploid males are viable they would be killed before leaving the nest (Francini et al. 2012), diploid males of Tetragonisca angustula were found in a reproductive aggregation close to the entrance of a queenless colony (Santos et al. 2013).

Here we investigate the fate of diploid males of Scaptotrigona depilis and aimed to answer the question: do diploid males leave their colonies to join mating aggregations? 
Table I. Age at collection and genotypes of diploid males of Scaptotrigona depilis in a reproductive aggregation.

\begin{tabular}{c|c|c|c|c|c|c|c}
\hline \multirow{2}{*}{$\begin{array}{c}\text { Colony } \\
\text { and male }\end{array}$} & \multirow{2}{*}{ Age (days) } & \multicolumn{7}{|c}{ Males' genotypes at locus } \\
\cline { 3 - 8 } & & T1 & T3 & T4 & T8 & Sxant 06 & Sxant 18 \\
\hline 1-a & 18 & $140 / 142$ & $125 / 129$ & $132 / 140$ & $147 / 153$ & $175 / 177$ & $172 / 192$ \\
\hline $1-\mathrm{b}$ & 15 & $140 / 142$ & $125 / 129$ & $132 / 138$ & $153 / 153$ & $177 / 181$ & $170 / 172$ \\
\hline $2-\mathrm{c}$ & 19 & $138 / 142$ & $125 / 129$ & $132 / 140$ & $147 / 153$ & $177 / 179$ & $172 / 174$ \\
\hline
\end{tabular}

In order to answer this question, two free-foraging colonies kept in wooden boxes in the Biology Department at São Paulo University (Ribeirão Preto, Brazil) were utilised. These colonies were chosen because their queens were producing diploid males, as previously confirmed through genotyping ten male pupae from each colony following the methods described below. We collected brood combs containing mature pupae and let the bees emerge in an incubator. Thirty newly emerged males of each colony were marked with nontoxic paint (Revell GmbH \& Co. KG, Germany) on their thorax for six days, using a different colour for each day (total 360 marked males) and all the males were reintroduced into their natal nest on the day of marking. During the time of the study, the mating aggregations were observed twice a day, and any marked males present were collected. They were preserved in absolute ethanol for genetic analysis. The DNA was extracted using the Chelex method and males were genotyped at six microsatellite loci, T1, T3, T4 and T8 (Paxton et al. 1999), and Sxant06 and Sxant18 (Duarte et al. 2011). Microsatellite amplification and visualization were done as described previously by Francisco et al. (2011). Males were categorized as diploid if they were heterozygous at one or more loci (Alves et al. 2011).

Five marked males were found at two mating aggregations which were approximately 20 meters from their natal colonies. Three of them were diploid, since almost all loci showed two different alleles (Table 1), whereas the other two were likely haploid. The age of diploid males within the aggregation ranged from 15 to 20 days old (Table 1), and the haploid were from 16 and 20 days old.

These findings suggest that the presence of stingless bee diploid males in mating aggregations may be more common than previously suspected. Our data are in accordance with those obtained by Santos et al. (2013), who also found diploid males in a mating aggregation of $T$. angustula. Although the workers of stingless bees are supposed to recognize and kill diploid males inside the nests (Francini et al. 2012), it is clear that some of these escape worker policing, depart from their colonies, and become a member of a reproductive aggregation (Santos et al. 2013; this study). It is important to note that removing the brood combs and allowing the pupae to emerge out of the colony context might have enhanced their survival. However, no aggressive behaviour towards males in colonies producing diploid males during their emergence was observed (this study). Camargo (1982) verified that the average lifespan of diploid males of M. quadrifasciata is only three days, while haploid males live 15 days on average, both in artificial conditions. The average lifespans of haploid and diploid males of 
S. depilis were not compared, but if there are any physiological constraints that limit the diploid males' life span, at least some of them must live long enough to be able to join mating aggregations.

Some new information about the mating strategies of $S$. depilis males was discovered. Despite the fact that stingless bee males disperse away from their natal nests to avoid inbreeding (Paxton 2000; Cameron et al. 2004; Kraus et al. 2008), some of them (haploid or diploid) join aggregations very close to their original colonies. It is important to note that this is a managed population kept in a stingless bee apiary maintaining up to 100 nests in a small area. Further research on this topic is needed to draw stronger conclusions.

These results add more precision as to the age of sexual maturity age of male stingless bees, since previous studies considered only the age that males of leave the nest (an average of 18.6 days old in M. favosa; van Veen et al. 1997). It is showed here that both haploid and diploid males join mating aggregations from 15 to 20 days old. It was not possible to ascertain that this was their first experience in a mating aggregation since they could have already visited one previously. However, considering that Pech-May et al. (2012) found that $M$. beecheii males are sexually mature at $c a$. 14 days old, it is possible that males of $S$. depilis also mature later in life, and would join reproductive aggregations only when mature.

Despite the few diploid males found in mating aggregation compared to the marking effort and presence of approximately one thousand individuals therein, there is a great chance that a much higher fraction of diploid males produced by S. depilis leave the nest to search for an aggregation site, since there is good evidence that males disperse from their natal nests (Cameron et al. 2004; Kraus et al. 2008). This could also explain why only $c a$. $1.4 \%$ of the marked males were recaptured. Probably, the majority of males had dispersed to distant aggregations that we did not sample. However, some did not disperse and thus increased the risks of inbreeding. It is important to note that our manipulation may have allowed the males to live normally by minimizing worker policing. Additionally, diploid male production in social insects under monandry is predicted to be very high, since half of the diploid brood are diploid males when a matched mating is performed. As this species produces approximately 200 or more new brood cells per day (this study), even if just a small fraction of the diploid males succeeded in leaving the nest, the total amount could be high.

All these factors together (high rate of production of diploid males, survivorship, and visit to mating sites) strongly suggest that diploid males could be dangerous to stingless bee populations from the females' point of view (Harpur et al. 2013). Further research is needed to verify the potential mating success of $S$. depilis diploid males, since we had no success when testing this under controlled conditions, following the protocol established by Engels and Engels (1984). If it is established that diploid males of $S$. depilis can successfully mate, this would suggest that this species is under a higher risk of extinction due to the decreased fitness of queens that mate with them (Zayed 2009; Harpur et al. 2013). 


\section{Acknowledgements}

We thank FAPESP (Fundação de Amparo à Pesquisa do Estado de São Paulo, 2012/11144-0 to AVN; 2010/19717-4 to DAA; 2012/16716-2 to JPF), CNPq (Conselho Nacional de Desenvolvimento Científico e Tecnológico, 470372/2013-3 to DAA; 500458/2013-8 to CFS), PNPD/CAPES (Programa Nacional de Pós-Doutorado da Coordenação de Aperfeiçoamento de Pessoal de Nível Superior, to DAA) and BioComp - NAP-USP (Research Center on Biodiversity and Computing of the Universidade de Sáo Paulo, to JPF, MN and DAA) for financial support.

\section{References}

Alves DA, Imperatriz-Fonseca VL, Francoy TM, Santos P, Billen J, Wenseleers T (2011) Successful maintenance of a stingless bee population despite a severe genetic bottleneck. Conservation Genetics 12(3): 647-658. doi: 10.1007/s10592-010-0171-z

Camargo CA (1982) Longevity of diploid males, haploid males, and workers of the social bee Melipona quadrifasciata Lep. (Hymenoptera: Apidae). Journal of the Kansas Entomological Society 55(1): 8-12.

Camargo CA (1979) Sex determination in bees. XI Production of diploid males and sex determination in Melipona quadrifasciata. Journal of Apicultural Research 18: 77-84.

Cameron EC, Franck P, Oldroyd BP (2004) Genetic structure of nest aggregations and drone congregations of the southeast Asian stingless bee Trigona collina. Molecular Ecology 13(8): 2357. doi: 10.1111/j.1365-294x.2004.02194.x

Cook J, Crozier RH (1995) Sex determination and population biology in the Hymenoptera. Trends in Ecology and Evolution 10: 281-286. doi: 10.1016/0169-5347(95)90011-X

Cowan DP, Stahlhut JK (2004) Functionally reproductive diploid and haploid males in an inbreeding hymenopteran with complementary sex determination. Proceedings of the National Academy of Sciences USA 101(28): 10374-10379. doi: 10.1073/pnas.0402481101

Duarte OMP, Gaiotto FA, Souza AP, Mori GM, Costa MA (2011) Isolation and characterization of microsatellites from Scaptotrigona xanthotricha (Apidae, Meliponini): a stingless bee in the Brazilian Atlantic rainforest. Apidologie 43(2): 432-435.

El Agoze M, Drezen J, Renault S, Periquet G (1994) Analysis of the reproductive potential of diploid males in the wasp Diadromus pulchellus (Hymenoptera: Ichneumonidae). Bulletin of Entomological Research 84(2): 213-218. doi: 10.1017/S0007485300039717

Engels E, Engels W (1984) Drone aggregations near the nest of the stingless bee, Scaptotrigona postica. Apidologie 15(3): 315-328. doi: 10.1051/apido:19840304

Francini IB, Nunes-Silva CG, Carvalho-Zilse GA (2012) Diploid male production of two Amazonian Melipona bees (Hymenoptera: Apidae). Psyche 2012: ID 484618.

Francisco FO, Brito RM, Santiago LR, Gonçalves PHP, Pioker FC, Domingues-Yamada AMT, Arias MC (2011) Isolation and characterization of 15 microsatellite loci in the stingless bee Plebeia remota (Apidae: Meliponini). Conservation Genetics Resources 3(3): 417-419. doi: 10.1007/s12686-010-9369-0 
Harpur BA, Sobhani M, Zayed A (2013) A review of the consequences of complementary sex determination and diploid male production on mating failures in the Hymenoptera. Entomologia Experimentalis et Applicata 146(1): 156-164. doi: 10.1111/j.1570-7458.2012.01306.x

Heimpel GE, de Boer JG (2008) Sex determination in the Hymenoptera. Annual Review of Entomology 53: 209-230. doi: 10.1146/annurev.ento.53.103106.093441

Kraus FB, Weinhold S, Moritz RFA (2008) Genetic structure of drone congregations of the stingless bee Scaptotrigona mexicana. Insectes Sociaux 55(1): 22-27. doi: 10.1007/s00040007-0966-1

Kureck IM, Nicolai B, Foitzik S (2013) Similar performance of diploid and haploid males in an ant species without inbreeding avoidance. Ethology 119: 360-367. doi: 10.1111/ eth. 12073

Packer L, Owen R (2001) Population genetic aspects of pollinator decline. Conservation Ecology 5(1): 4 .

Paxton RJ (2000) Genetic structure of colonies and a male aggregation in the stingless bee Scaptotrigona postica, as revealed by microsatellite analysis. Insectes Sociaux 47(1): 63-69. doi: $10.1007 / \mathrm{s} 000400050010$

Paxton RJ, Weissschuh N, Quezada-Euán JJG (1999) Characterization of dinucleotide microsatellite loci for stingless bees. Molecular Ecology 8(4): 690-692. doi: 10.1046/j.1365294x.1999.00874.x

Pech-May FG, Medina-Medina L, May-Itzá WJ, Paxton RJ, Quezada-Euán JJG (2012) Colony pollen reserves affect body size, sperm production and sexual development in males of the stingless bee Melipona beecheii. Insectes Sociaux 59: 417-424. doi: 10.1007/s00040012-0236-8

Peters JM, Queller DC, Imperatriz-Fonseca VL, Roubik DW, Strassmann JE (1999) Mate number, kin selection and social conflicts in stingless bees and honeybees. Proceedings of the Royal Society of London B 266(1417): 379-384. doi: 10.1098/rspb.1999.0648

Santos CF, Menezes C, Imperatriz-Fonseca VL, Arias MC (2013) A scientific note on diploid males in a reproductive event of a eusocial bee. Apidologie 44(5): 519-521. doi: 10.1007/ s13592-013-0202-0

van Veen JW, Sommeijer MJ, Meeuwsen F (1997) Behaviour of drones in Melipona (Apidae, Meliponinae). Insectes Sociaux 44(4): 435-447. doi: 10.1007/s000400050063

Whiting P (1943) Multiple alleles in complementary sex determination of Habrobracon. Genetics 28(5): 365-382.

Zayed A (2009) Bee genetics and conservation. Apidologie 40(3): 237-262. doi: 10.1051/ apido/2009026

Zayed A, Packer L (2005) Complementary sex determination substantially increases extinction proneness of haplodiploid populations. Proceedings of the Natonal Academy of Sciences USA 102(30): 10742. doi: 10.1073/pnas.0502271102 